Derecho \& Realidad

Núm. 23 • I semestre de 2014

Facultad de Derecho y Ciencias Sociales, UPTC

ISSN: 1692-3936

\title{
La procedencia excepcional de la acción de tutela para el cobro de acreencias laborales: una vía para la protección de los DESC
}

\author{
Exceptional provenance of amparo suit for \\ payment of labor claims: a way for protection \\ of economic, social and cultural rights
}

\author{
Ana Patricia Pabón Mantilla* \\ Aury Mayerly Acevedo Suárez, Stella Mosquera**
}

\section{Resumen}

Los derechos económicos, sociales y culturales (DESCS) son los que posibilitan un nivel de vida adecuado para las personas. Estos derechos han sido objeto de declaraciones universales (Pacto Internacional de Derechos Económicos, Sociales y Culturales -PIDESC-de 1966), además han sido reconocidos por nuestra Carta Política. Es importante determinar que en el marco de estos derechos podemos hablar de acceso, condiciones de empleo, seguridad social, entre otros temas de gran importancia. Este trabajo pretende estudiar los mecanismos creados para hacer exigibles estos derechos, mediante el desarrollo de una línea jurisprudencial que tiene por objeto determinar si el no pago de las acreencias laborales vulnera el derecho al mínimo vital, y si de esta manera procede la acción de tutela como mecanismo de defensa.

* Abogada y filósofa de la Universidad Industrial de Santander, especialista en docencia universitaria de la misma universidad. Actualmente es docente investigadora de la Facultad de Derecho de la Universidad de Santander, directora del Centro de Investigaciones de la misma Facultad y directora de semillero de investigación en jurisprudencia constitucional. Correo electrónico: anapatricia.pabon@gmail.com

** Estudiantes de Derecho de la Universidad de Santander, y jóvenes investigadoras vinculadas al semillero. Correos electrónicos:, aurypiscis@hotmail.com, mosquerastella@gmail.com 
Derecho y Realidad

\section{Palabras clave}

Derechos económicos, sociales y culturales (DESC), acción de tutela, derecho al mínimo vital.

\section{Abstract}

The economic, social and cultural rights are those rights which enable an adequate level of living for the people. These rights have been the subject of universal statements (International Covenant on Economic, Social and Cultural Rights, ICESCR, 1966), and also have been recognized by our Constitution. It is important to determine that in the context of these rights we can talk about access, conditions of employment, social security, among other issues of great importance. This work aims to study the mechanisms of enforcing these rights through the development of a line of jurisprudence that seeks to determine if the non-payment of labor claims violates the right to the subsistence level, and if thus the amparo suit as a defense mechanism is feasible.

\section{Key words}

Economic, social and cultural rights, amparo suit, right to the subsistence level. 


\section{Presentación del problema}

Los derechos económicos, sociales y culturales (DESCS) tradicionalmente han tenido un trato diferente frente a su exigibilidad y justiciabilidad, con relación a otros derechos como los individuales y políticos. Durante mucho tiempo se estuvo más o menos de acuerdo en que su protección y su aseguramiento estaban limitados a la situación económica del Estado ${ }^{1}$. Esta noción ha ido cambiando y se ha logrado promover la idea de que el no garantizar dichos derechos hace si no imposible, por lo menos difícil el goce y disfrute de los derechos civiles y políticos.

Los DESC pueden ser definidos como aquellos derechos que posibilitan un nivel de vida adecuado para las personas y que cubren áreas como la igualdad material entre hombres y mujeres, el acceso y condiciones de empleo, la seguridad social, la protección a la familia, los niños y adultos mayores, el disfrute de los bienes de la cultura, la alimentación, la vivienda, la educación, la salud física y mental, entre otros.

Estos derechos han sido consagrados no solo en la Constitución sino que además han sido objeto de declaraciones y tratados internacionales en donde el Estado colombiano se compromete a asegurar su protección ${ }^{2}$.

A pesar de ello aún no se han implementado mecanismos efectivos de exigibilidad y justiciabilidad de estos derechos, pues existe la limitación frente a los recursos del Estado. Sin embargo, aunque explícitamente la reglamentación legal de la tutela la excluye como mecanismo de defensa de los DESC, a través de la jurisprudencia de la Corte Constitucional se han desarrollado importantes líneas jurisprudenciales en donde se logra la protección de algunos DESC cuando algunos actos u omisiones amenazan con vulnerar derechos fundamentales. A partir de dichas reglas jurisprudenciales se crean los derechos fundamentales por conexidad, logrando exigir mediante el mecanismo expedito de la tutela, la protección de estos derechos.

Ese es el caso de la línea jurisprudencial que asegura la procedencia excepcional de la acción de tutela para el cobro de salarios adeudados a los trabajadores, cuando este es su único sustento. Estos hechos, en principio, no son objeto de protección mediante la acción de tutela, pero se han hecho susceptibles de reclamación por

El art. 26 de la Convención Americana de Derechos Humanos consagra el desarrollo progresivo que consiste en la obligación que asumen los Estados de tratar de ir mejorando las condiciones frente al goce de los DESC, progresividad condicionada a la disponibilidad de los recursos económicos del Estado.

2 El Pacto Internacional de Derechos Económicos, Sociales y Culturales (PIDESC) de 1966 en donde además se creó el órgano encargado de controlar las obligaciones de los estados firmantes (Comité de DESC). 
Derecho y Realidad

esta vía cuando se afecta el mínimo vital del trabajador y su familia, si el Estado o los particulares le adeudan salarios.

A continuación se expondrá brevemente el desarrollo jurisprudencial que ha dado la Corte dentro de la línea que responde al problema jurídico planteado, y que hace parte de la discusión acerca de la procedencia de la acción de tutela como mecanismo para exigir el respeto de derechos que no son inicialmente considerados dentro de la lista de derechos fundamentales o individuales. Para ello se determinará en primer término el concepto de mínimo vital, derecho afectado con el no pago de salario como remuneración que garantiza a un trabajar su disfrute, posteriormente se expondrán propiamente las sentencias relevantes dentro de la línea, y finalmente se presentarán algunas conclusiones.

\section{El mínimo vital como un derecho fundamental}

La Corte Constitucional se ha manifestado en varias oportunidades sobre la procedencia excepcional de la acción de tutela para el cobro de salarios, cuando con el no pago de estos se vulnere el derecho fundamental al mínimo vital.

El mínimo vital ha sido considerado por la Corte como el conjunto de elementos necesarios para cubrir las necesidades básicas indispensables para garantizar la subsistencia digna de la persona y de su familia. El asegurar estas condiciones está en cabeza del Estado, y con mayor razón cuando se trata de uno que se ha denominado social de derecho y que tiene como deber ofrecer bienestar social y económico a los ciudadanos, para que cada persona viva dignamente dentro de las posibilidades económicas que estén a su alcance.

El concepto de mínimo vital reúne las condiciones de vida básicas como la alimentación, el vestido, la salud, la recreación, todos identificados con los denominados DESC; para satisfacer estas necesidades, es importante que la asignación que recibe una persona pueda cubrir estos gastos mínimos.

El no pago oportuno de los salarios, como asignación que tiene el trabajador o su familia para su subsistencia, configura una violación al derecho fundamental del mínimo vital y móvil de los trabajadores, por cuanto se está negando su bienestar integral y las posibilidades para proveerlo por sus propios medios.

El mínimo vital y móvil se ha configurado como un derecho en el ámbito jurisprudencial, pues la Corte ha definido, aclarado y señalado los eventos en los que se viola dicho derecho. Los casos resueltos en torno a la violación de este han sido la base para la formación de un precedente constitucional esencial en el área laboral, que equilibra la diferencia entre empleador y trabajador, y busca el bienestar 
de los asociados, con lo que se asegura una de las funciones del estado social de derecho.

\section{Desarrollo de la línea jurisprudencial}

La línea tiene como problema jurídico el determinar si el no pago de salarios a los trabajadores constituye una vulneración al derecho fundamental al mínimo vital que permita la procedencia de la acción de tutela como mecanismo de defensa. Como sentencia arquimédica se encuentra la T- 229 del 2007, en la que a un trabajador vinculado como contratista no le han cancelado tres quincenas de su salario, ocasionándole con ello un grave perjuicio a él y a su familia. La Corte reitera las reglas sobre la procedencia de la tutela para el cobro de salarios y reitera que existe presunción de veracidad frente a los hechos que narra el demandante si la demandada o el juez no logran desvirtuarlos.

Como sentencias hito se identifican las sentencias SU-995 de 1999 y la T- 148 del 2002. La primera es relevante en tanto se unifican las posiciones en el interior de la Corte sobre el problema y se definen los criterios para dar respuesta al problema planteado en forma afirmativa, y en lo que se espera sea la decisión precedente para tomar en cuenta en casos futuros con el fin de asegurar el derecho a la igualdad. En dicho pronunciamiento, la Corte revisa las tutelas presentadas por un grupo de docentes trabajadores del Estado a quienes se les adeuda el pago de sus salarios y algunas primas.

En este pronunciamiento, la Corte señala que el pago oportuno de la remuneración salarial es

una garantía que no se agota en la simple enunciación de un deber surgido de la relación laboral, sino que se trata de un verdadero derecho fundamental. La cumplida cancelación del salario está íntimamente ligada a la protección de valores y principios básicos del ordenamiento jurídico, que velan por la igualdad de los ciudadanos, el ideal de un orden justo, el reconocimiento de la dignidad humana, el mínimo material sobre el cual puede concretarse el libre desarrollo de la personalidad, y se realiza el amparo de la familia como institución básica de la sociedad (Corte Constitucional, Sentencia SU-995, 1999).

Ahora, por regla general ante el no cubrimiento de esta obligación por parte de los empleadores, el trabajador tiene como recurso el acceso a la jurisdicción laboral; sin embargo existen ocasiones en que se justifica acudir a una vía de excepción, cuando lo que está en juego es la garantía de los derechos fundamentales. En estos casos

se tiene que apelar a mecanismos que tiendan a maximizar su pronta eficacia; 
es decir, que logren, dentro del marco de las herramientas jurídicas disponibles, proteger a todas las personas titulares de los mismos, que sufren un perjuicio irremediable si no reciben una protección inmediata de parte de los órganos del Estado; en este caso, todas las personas que derivan su existencia y bienestar personal y familiar de una remuneración, en medio de una economía inestable, en la que las estructuras de producción y distribución del ingreso, y el libre juego de las relaciones de mercado, no pueden, por sí solas, producir el orden justo en el que se debe basar la convivencia pacífica (Corte Constitucional, Sentencia SU-995, 1999).

Para determinar en qué casos estaría una persona ante un perjuicio irremediable, la Corte estableció algunos criterios de procedibilidad de la acción de tutela frente al cobro de acreencias laborales. Tales reglas se sintetizan como sigue:

a. Cuando se invoca como mecanismo pronto y eficaz contra la violación de uno de sus derechos fundamentales ${ }^{3}$. Como en este caso del derecho innominado al mínimo vital.

b. Para evitar que el trabajador sufra una situación crítica económica y psicológica. Es decir cuando se trate de resolver el pago ante situaciones injustificadas, inminentes y graves que hacen urgente la intervención del juez de tutela pues la jurisdicción ordinaria se muestra insuficiente.

c. Que el trabajador no cuente con ingresos suficientes y distintos de los que provienen de su trabajo para mantener su subsistencia en forma digna.

La Corte advierte que el Juez es libre de hacer uso de los mecanismos probatorios que dentro del trámite de tutela puedan darse para garantizar el debido proceso de las partes. También advierte que la orden de reconocimiento que imparte el juez de tutela debe extenderse a todas las sumas de dinero adeudadas al momento de presentación de la tutela y que razones como la insolvencia del empleador no justifican el no pago oportuno de la obligación salarial con sus trabajadores.

En la sentencia T -148 de 2002, la Corte revisa el caso de una docente a quien el municipio le adeudaba cuatro meses de salario, la Corte analiza el caso y agrega una nueva regla a las ya señaladas e indica que la tutela procede siempre que se verifiquen las siguientes reglas:

3 Sobre la definición de los criterios para determinar el carácter fundamental de los derechos, siempre será provechosa la referencia a la Sentencia T-02 de 1992, reiterada y perfeccionada a lo largo de la historia de la Corte Constitucional. 
1) Que exista un incumplimiento en el pago del salario al trabajador;

2) Que dicho incumplimiento comprometa el mínimo vital de la persona. Lo que se presume cuando:

a) El incumplimiento es prolongado o indefinido.

b) El incumplimiento sea superior a dos meses, excepto si la persona recibe como contraprestación a su trabajo un salario mínimo, caso en el cual no está obligada a esperar a que pasen los dos meses.

3) La presunción de afectación del mínimo vital debe ser desvirtuada por el demandado o por el juez, al demandante le basta con alegar y probar siquiera sumariamente que el incumplimiento salarial lo deja en una situación crítica, por carecer de otros ingresos o recursos diferentes al salario que le permitan asegurar su subsistencia.

4) Los argumentos económicos, presupuestales o financieros no son razones que justifiquen el incumplimiento en el pago de los salarios adeudados al trabajador.

Con esto, la Corte agrega como subregla el periodo a partir de cual procede la acción de tutela.

\section{Conclusión}

La Corte, a partir de la consolidación de las subreglas referidas, ha reiterado su posición frente a la procedencia excepcional de la tutela como mecanismo de defensa que busca evitar la continuación en la vulneración del derecho al mínimo vital del trabajador al que le adeudan salarios.

La acción de tutela se muestra como un mecanismo idóneo para la protección no solo de los derechos fundamentales individuales, sino, como opera en este caso, de derechos económicos, sociales y culturales, mostrando con ello que existe una estrecha relación entre estos derechos, y que de no protegerse los últimos finalmente se estarían amenazando los primeros.

El derecho a recibir un salario en forma oportuna y a gozar de la seguridad social, constituye un DESC por ser una garantía dentro de las condiciones de empleo, en la línea expuesta se observa como la tutela constituye una herramienta efectiva para la defensa de los derechos de los trabajadores en esta área. Las reglas jurisprudenciales esbozadas por la Corte han logrado la reparación y cese en la violación del derecho al mínimo vital, y a la subsistencia por el incumplimiento en el pago de salarios y asegura el derecho de los trabajadores y sus familias a tener una vida digna y a poder suplir sus necesidades básicas para lograr la subsistencia en un país sin equilibrio social.

Con esto, la justiciabilidad de los DESC encuentra una herramienta efectiva y ágil cuando se trata de proteger a personas en especial situación de vulnerabilidad. 


\section{Referencias}

Convención Americana de Derechos Humanos.

Corte Constitucional. (1994). Sentencia T- 167.

Corte Constitucional. (1999). Sentencia SU-995.

Corte Constitucional. (2001). Sentencia T-1088.

Corte Constitucional. (2002). Sentencia T-148.

Corte Constitucional. (2006). Sentencia T- 146.

Corte Constitucional. (2007). Sentencia T-229.

Pacto Internacional de Derechos Económicos, Sociales y Culturales (PIDESC). 